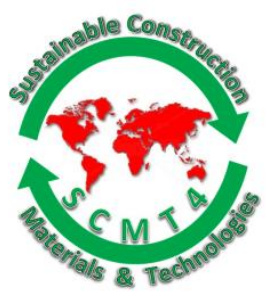

SCMT4

Las Vegas, USA, August 7-11, 2016

\title{
Characterization of Hot-Mix Asphalt Containing Reclaimed Asphalt Pavement Material in Cold Climate: An Alaskan Experience
}

\author{
Jenny Liu ${ }^{1 a}$, and Sheng Zhao ${ }^{1 b}$ \\ ${ }^{1}$ University of Alaska Fairbank, Fairbanks, AK, USA. \\ ${ }^{1 a}$ Email:< jliu6@alaska.edu>, ${ }^{1 b}$ Email: <szhao4@alaska.edu>.
}

\begin{abstract}
Reclaimed asphalt pavement (RAP) has been used for several decades in hot-mix asphalt (HMA) for paving purposes due to environmental and economical benefits. However, concerns still exist regarding using RAP in cold climate, as the dramatic increase in stiffness of HMA when RAP is added may lead to severe low temperature cracking. Meanwhile, if softer binder is used to compensate the stiffness increase in HMA containing RAP, heavy traffic rutting and moderate low-temperature cracking may occur. The above-mentioned concerns have limited RAP use in cold climate, especially in places like Alaska containing various climatic conditions, although there is currently a tendency of using high RAP content in asphalt industry. This paper presents a study to systematically characterize Alaskan HMA materials containing RAP. The HMA contained up to 35\% RAP, including two regional asphalt binders, PG 52-28, and PG 52-40. The characterization included dynamic modulus, flow number and IDT creep tests. It was found that adding RAP led to higher dynamic modulus, higher flow number, and higher IDT creep stiffness of the mixture regardless of testing temperature, which means adding RAP could potentially result in a mixture with higher rutting resistance and lower low temperature cracking resistance. The results were found to be consistent on both PG 52-28 mixes and PG 52-40 mixes produced with materials from the Alaska Department of Transportation \& Public Facilities (ADOT\&PF) Northern Region. More complete evaluation from more mixes in Alaska and more performance related tests were recommended for future studies.
\end{abstract}

\section{INTRODUCTION}

Reclaimed asphalt pavement (RAP) has been used for several decades in hot-mix asphalt (HMA) for paving purposes. The use of RAP reduced demand for new or virgin aggregates and asphalt binders (Huang et al. 2004; Behnia et al. 2010) leading to significant environmental and economical benefits. A saving from 14 to $34 \%$ was estimated for a RAP content ranging between 20 to 50\% in HMA pavements (Kandhal and Mallick 1997). Another calculation method showed a 35\% saving with the use of 50\% RAP (Willis et al. 2012). However, the RAP content is limited in many states due to undetermined mix design methods and limited knowledge of production technology (Zaumanis and Mallick 2014). For example, Washington, Oregon, New Hampshire and Nebraska allow 20\%, 30\%, 30\% and 40-50\% RAP to be used in HMA under certain conditions, respectively. High-RAP contents, typically accepted as percentage 
greater than $25 \%$ and possibly exceeding $50 \%$, were further researched in the recent National Cooperative Highway Research Program (NCHRP) 09-46 project (West et al. 2013), which aimed at developing a mix design and analysis procedure for high-RAP mixes that provide satisfactory long-term performance.

Plenty of studies have been reported regarding evaluation of using RAP in HMA (McDaniel and Anderson 2001; AL-Qadi et al. 2007; Huang et al. 2011; Zhao et al. 2013). Generally, equivalent (or better) performance was expected when RAP was used at low or medium content level. When RAP content was increased, compromised fatigue and low temperature performance were reported (McDaniel and Anderson 2001; Huang et al. 2011). With the tendency of using high RAP content in asphalt industry, one critical question has been raised: How much old binder actually blends into newly added asphalt during mixing? Several attempts were conducted by researchers to address the blending degree issue (Huang et al. 2005; Bonaquist 2007; Bowers et al. 2014; Zhao et al. 2015). It was found that only a small portion of RAP binder was actually activated and blended with new asphalt, while other portions remained inactive leading to a stiff coating around RAP aggregates. According to Zaumanis and Mallick (2014), additional concerns that have limited RAP usage in HMA include mixture workability, potential emissions and production technology. However, with the recent advances in asphalt paving technology, mixtures containing 50\% RAP (Bonaquist 2007) or 100\% RAP (Hajj et al. 2008) have been reported to be routinely produced.

In states with cold climate such as Alaska, the concerns about using RAP can be specific. The dramatic increase in stiffness of HMA when RAP is added may lead to severe low temperature cracking. Meanwhile, if softer binder is used to compensate the stiffness increase in HMA containing RAP, heavy traffic rutting and moderate low-temperature cracking may occur. As an pioneering effort to address RAP usage in Alaska, one preliminary laboratory study was undertaken to investigate how three RAP contents added to HMA affect the blended binder (Saboundjian and Teclemariam 2010). Another project (Connor and $\mathrm{Li}$ 2009) focused on the performance of mix with the addition of 15\% RAP for airport runway reconstruction, and results showed that the addition of $15 \%$ RAP did not adversely impact the quality of the HMA. The above-mentioned studies may serve as good references regarding experience of RAP use in Alaska, however, the performance data on HMA containing RAP for surface course applications is limited. Therefore, it is essential to properly characterize typical Alaska HMA mixes containing RAP materials.

\section{OBJECTIVES}

The main objective of this study is to properly characterize Alaskan HMA materials containing RAP. The characterization will yield: (1) mix modulus (stiffness) values at different temperatures, to be used in pavement design/analysis procedures, (2) rutting performance at high temperature, and (3) lowtemperature cracking performance.

\section{EXPERIMENTAL INVESTIGATION}

\section{Materials}

In order to characterize Alaskan HMA containing RAP, a laboratory experimental program was developed and is presented in Table 1. Two asphalt binders typically used in the Alaska Department of Transportation \& Public Facilities (ADOT\&PF) Northern Region were used, including PG 52-28 base binder and PG 52-40 modified binder. RAP usage for PG 52-28 mixes was up to $25 \%$ and $35 \%$, respectively, while that for PG 52-40 mixes was $25 \%$ only. Both mixes were classified as Type II-B surface mixes in Alaska and tested in contrast to control mixes containing 0\% RAP. 
Table 1. Asphalt Mixes Evaluated in This Study

\begin{tabular}{|c|c|c|c|c|}
\hline Mix \# & Mix Name & Mix Type & RAP \% & Binder PG \\
\hline 1 & 5228-Control & & 0 & PG 52-28 \\
\hline 2 & 5228-RAP25 & \multirow{4}{*}{ Type II-B } & 35 & PG 52-28 \\
\cline { 4 - 4 } & 5228-RAP35 & & 0 & PG 52-28 \\
\hline 3 & 5240-Control & 25 & PG 52-40 \\
\hline 5 & 5240-RAP25 & & PG 52-40 \\
\hline
\end{tabular}

The HMA was produced in the laboratory according to the readily available job mix formulae (JMF) used by the same contractor that supplied aggregates. The same target JMF was used for all the mixes with the same binder for comparison purpose. The optimum asphalt contents for PG 52-28 mixes and PG 52-40 mixes were both $5 \%$. As the mix gradation was composed of combinations of coarse, intermediate, fine, and RAP aggregates, the target JMF gradation could not be completely repeated. Figure 1 shows the blended aggregate gradations and their conformity to the JMF for the PG 52-28 binder and the PG 52-40 binder, respectively.

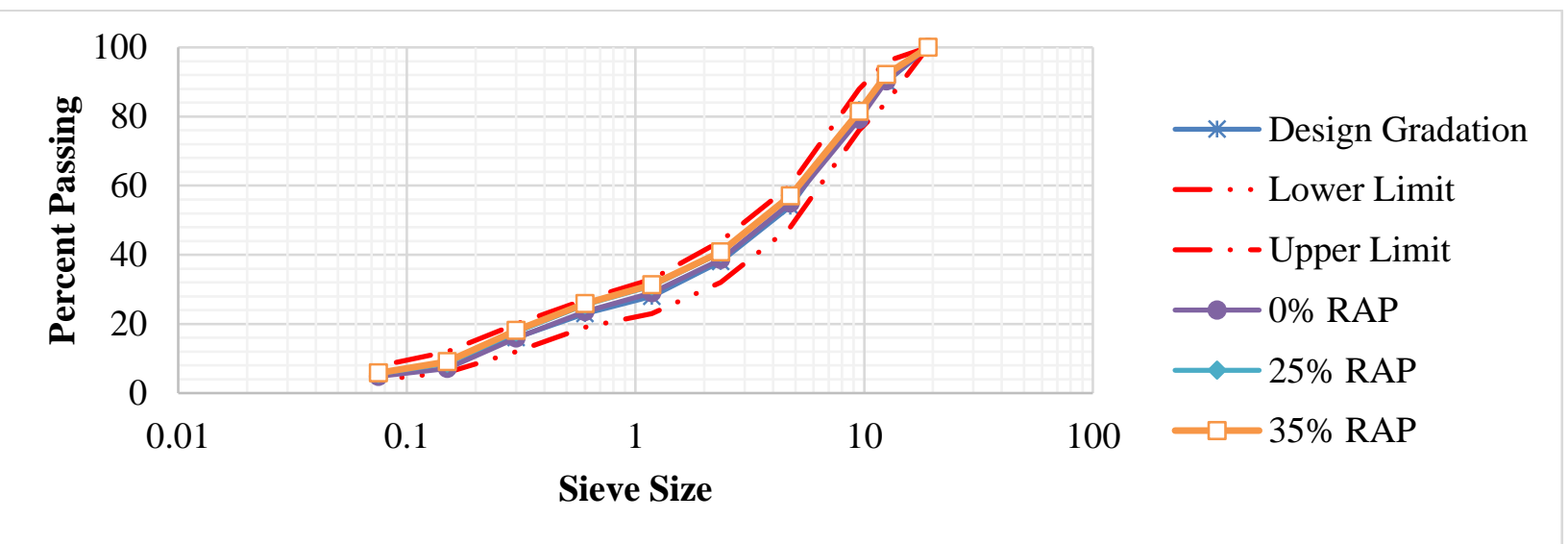

(a) Aggregate Gradation Curve for Mixes with PG 52-28 Binder

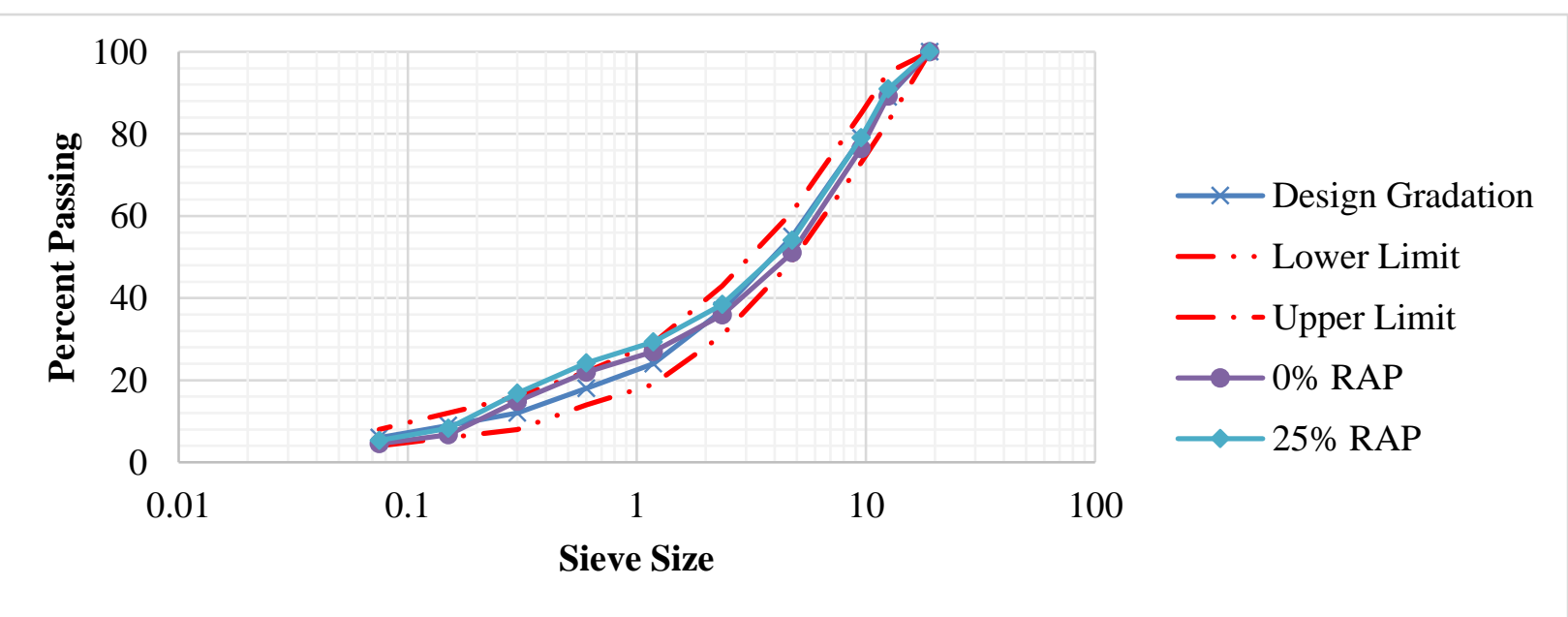

(b) Aggregate Gradation Curve for Mixes with PG 52-40 Binder

Figure 1. Aggregate Gradation Curves 
Laboratory Testing. Table 2 presents the laboratory testing plan. The target air voids for all the tests were $7 \pm 0.5 \%$. Laboratory tests included dynamic modulus ( $\left.1 \mathrm{E}^{* 1}\right)$ test from which the $1 \mathrm{E}^{*} \mathrm{l}$ master curve could be developed, flow number test for rutting evaluation and indirect tension (IDT) creep stiffness for low temperature cracking evaluation. Cylindrical samples were produced with the Superpave gyratory compactor (SGC) and sliced into target thicknesses for each specific test.

Table 2. Laboratory Testing Plan

\begin{tabular}{|c|c|c|c|}
\hline Test & Properties & Testing Temperature $\left({ }^{\circ} \mathbf{C}\right)$ & Target Air Voids \\
\hline \multirow{4}{*}{$\begin{array}{c}\text { Dynamic Modulus } \\
\left(\mathrm{lE}^{* 1)}\right.\end{array}$} & \multirow{5}{*}{ Modulus } & 4.4 & \multirow{10}{*}{$7 \pm 0.5 \%$} \\
\hline & & 21.1 & \\
\hline & & 37.8 & \\
\hline & & 54 & \\
\hline lE*1 Master Curve & & - & \\
\hline Flow Number & Rutting & 54 & \\
\hline \multirow{4}{*}{$\begin{array}{l}\text { IDT Creep } \\
\text { Stiffness }\end{array}$} & \multirow{4}{*}{$\begin{array}{l}\text { Low-Temperature } \\
\text { Thermal Cracking }\end{array}$} & 0 & \\
\hline & & -10 & \\
\hline & & -20 & \\
\hline & & -30 & \\
\hline
\end{tabular}

Dynamic modulus (lE*l) test was conducted at four temperatures according to AASHTO T 342 (2013), including $4.4^{\circ} \mathrm{C}, 21.1^{\circ} \mathrm{C}, 37.8^{\circ} \mathrm{C}$ and $54^{\circ} \mathrm{C}$ (Figure 2). Master curves were developed based on the dynamic modulus data for further analysis. Using the principle of time-temperature superposition of $1 \mathrm{E}^{*} 1$, a master curve was constructed by shifting the data at various temperatures to the reference temperature (usually $21.1^{\circ} \mathrm{C}$ ) with respect the time until the curves merge into a single smooth function. The results were calculated based on the average of three samples.

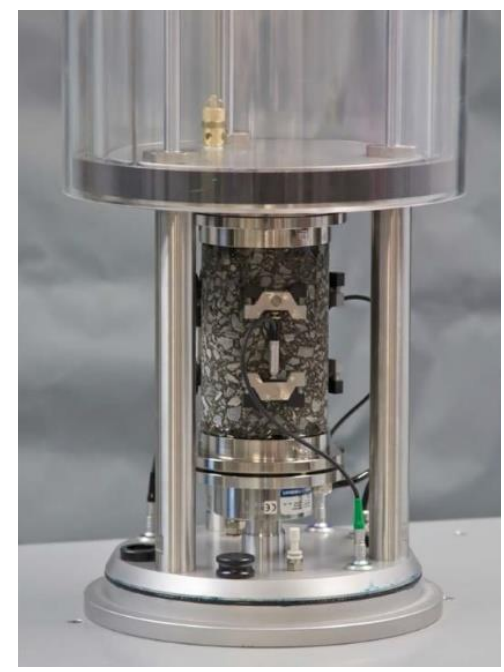

\section{Figure 2. Dynamic Modulus Tested by Asphalt Mixture Performance Tester (AMPT)}

Flow number test was conducted following AASHTO TP 79 (2013) on the same testing apparatus of dynamic modulus. Flow number samples before and after the test can be seen in Figure 3. For this study, $40{ }^{\circ} \mathrm{C}$ was determined as the High Adjusted PG Temperature using the long-term pavement performance (LTPP) Bind Version 3.1 Software and used as the testing temperature for flow number. The results were calculated based on the average of three samples. 


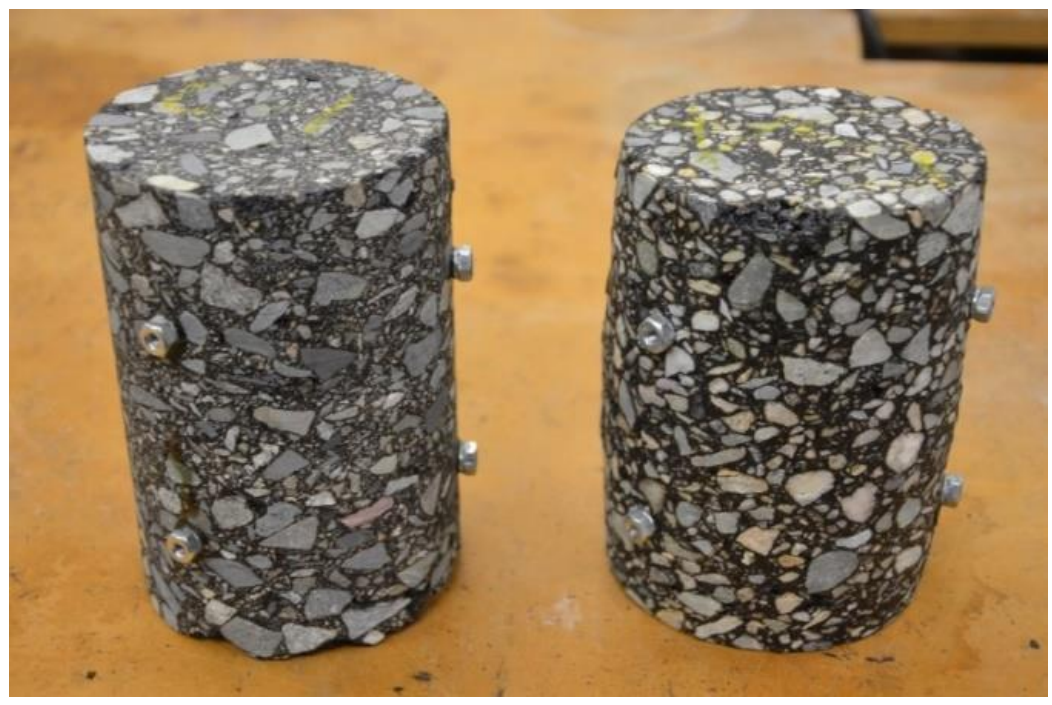

\section{Figure 3. Flow Number Sample before (left) and after (right) Testing}

Indirect tension (IDT) creep compliance was conducted according to AASHTO T 322 (AASHTO 2013, Figure 4). The 52-28 mixes were tested at $0{ }^{\circ} \mathrm{C},-10{ }^{\circ} \mathrm{C}$ and $-20{ }^{\circ} \mathrm{C}$, while $52-40$ mixes were tested at -10 ${ }^{\circ} \mathrm{C},-20{ }^{\circ} \mathrm{C}$ and $-30{ }^{\circ} \mathrm{C}$, respectively. According to the equations provided in AASHTO T 322 (2013), the creep stiffness of each mix from $0 \mathrm{~s}$ to $1000 \mathrm{~s}$ was recorded.

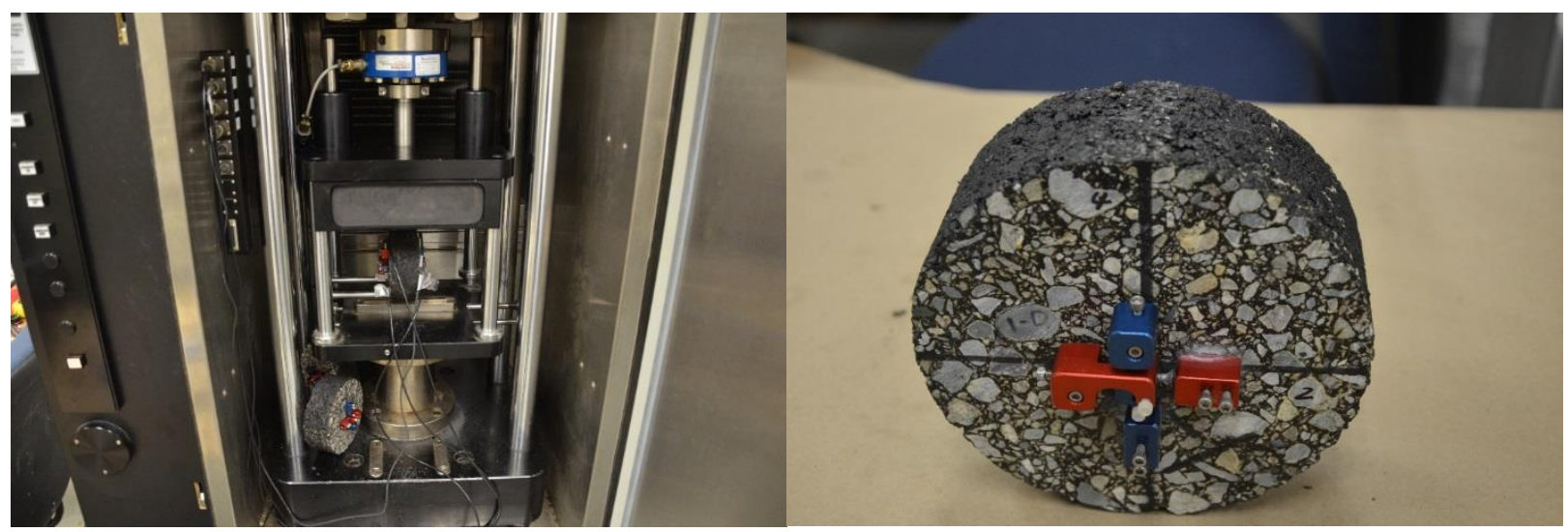

Figure 4. IDT Testing Set-up

\section{TESTING RESULTS}

Figure 5 shows $1 \mathrm{E}^{*} \mathrm{l}$ results tested at $4.4^{\circ} \mathrm{C}, 21.1^{\circ} \mathrm{C}, 37.8^{\circ} \mathrm{C}$ and $54^{\circ} \mathrm{C}$. The results are presented in terms of testing temperature with mixes of the same binder arranged in the same sub-figure. Figure 6 presents the master curves at reference temperature $21.1^{\circ} \mathrm{C}$. It is clear that dynamic modulus of both PG 52-28 and PG 52-40 mixtures follow the general trend, i.e. dynamic modulus increases with the increase in loading frequency. It can be seen that dynamic modulus of both PG 52-28 and PG 52-40 mixes were increased with the addition of RAP. The higher the RAP content, the higher the dynamic modulus. This observation indicates that adding RAP into Alaskan HMA might result in the improvement in rut-resistance of both PG 52-28 and PG 52-40 mixes regardless of temperature. 


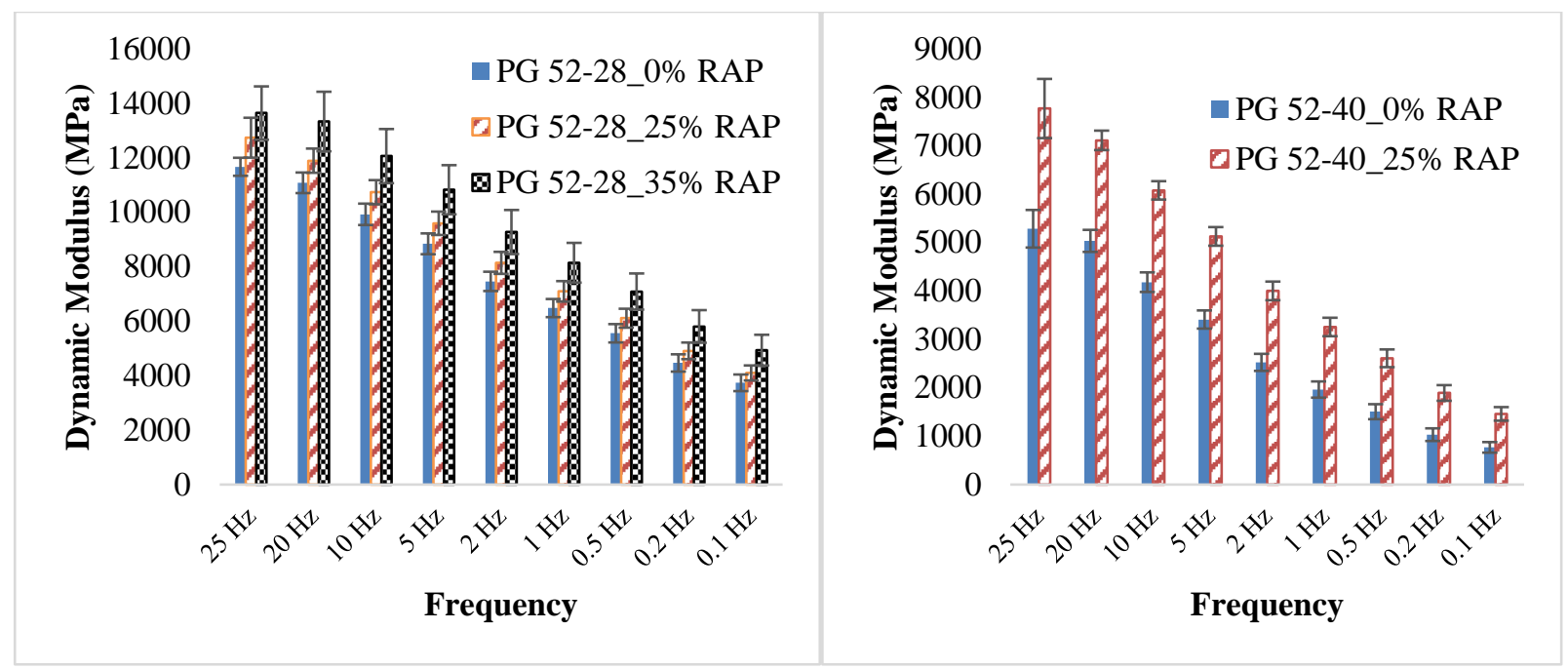

(a) Results Tested at $4.4^{\circ} \mathrm{C}$

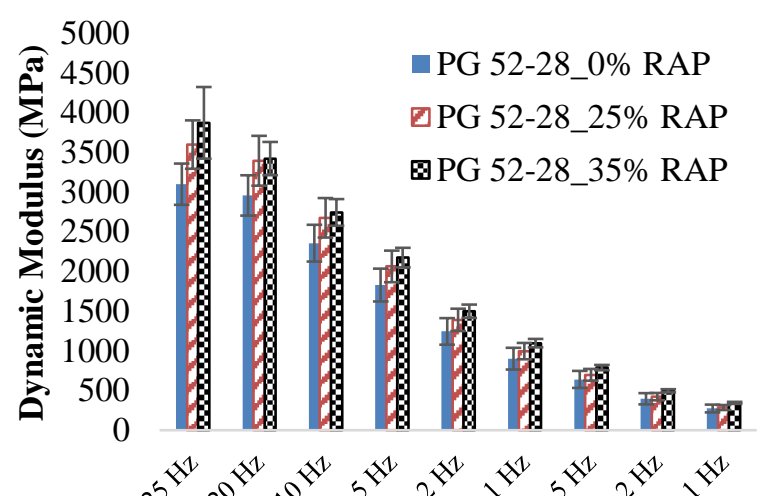

Frequency

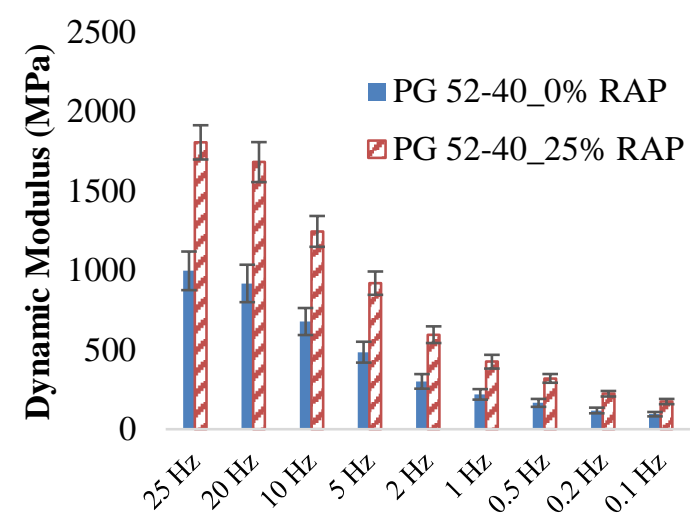

Frequency

(b) Results Tested at $21.1^{\circ} \mathrm{C}$

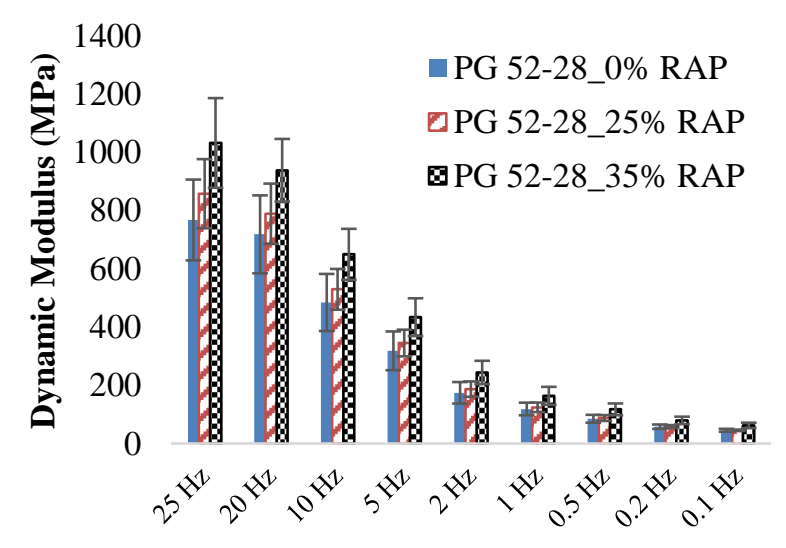

Frequency

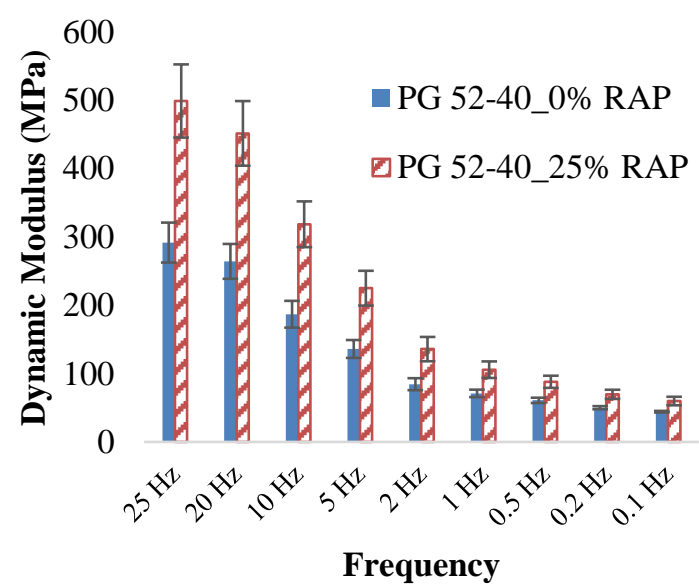

(c) Results Tested at $37.8^{\circ} \mathrm{C}$ 

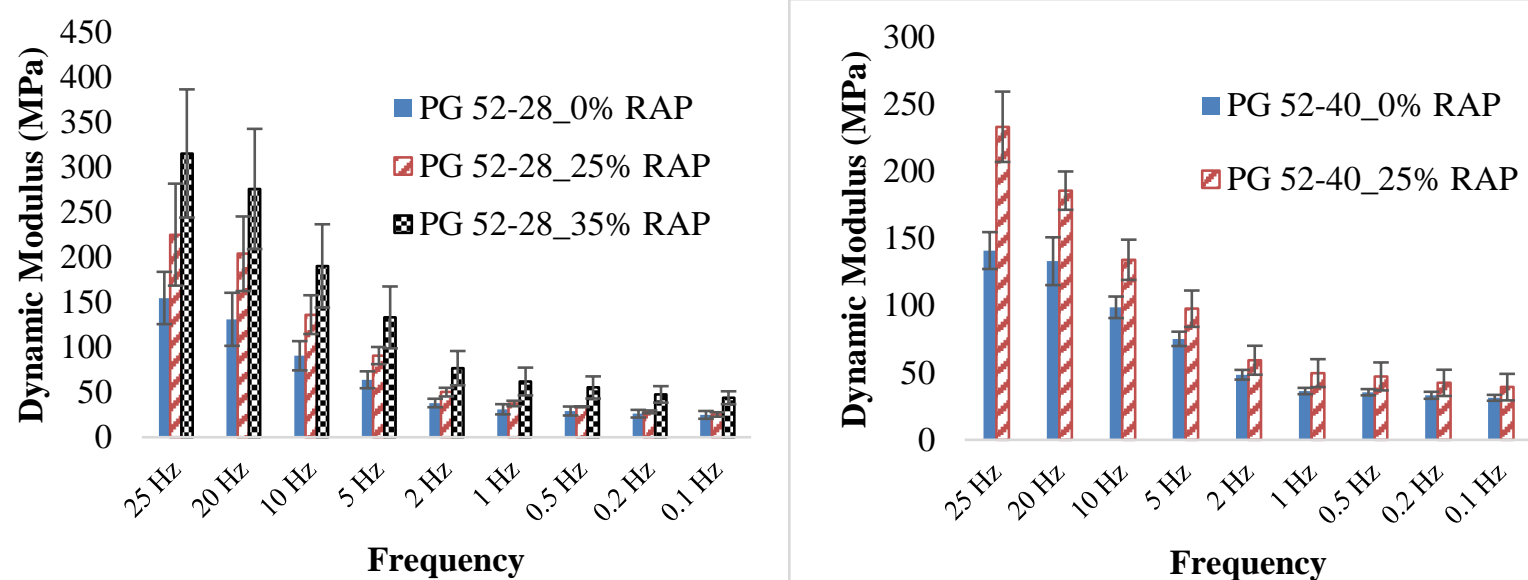

Frequency

(d) Results Tested at $54^{\circ} \mathrm{C}$

Figure 5. IE*I Results

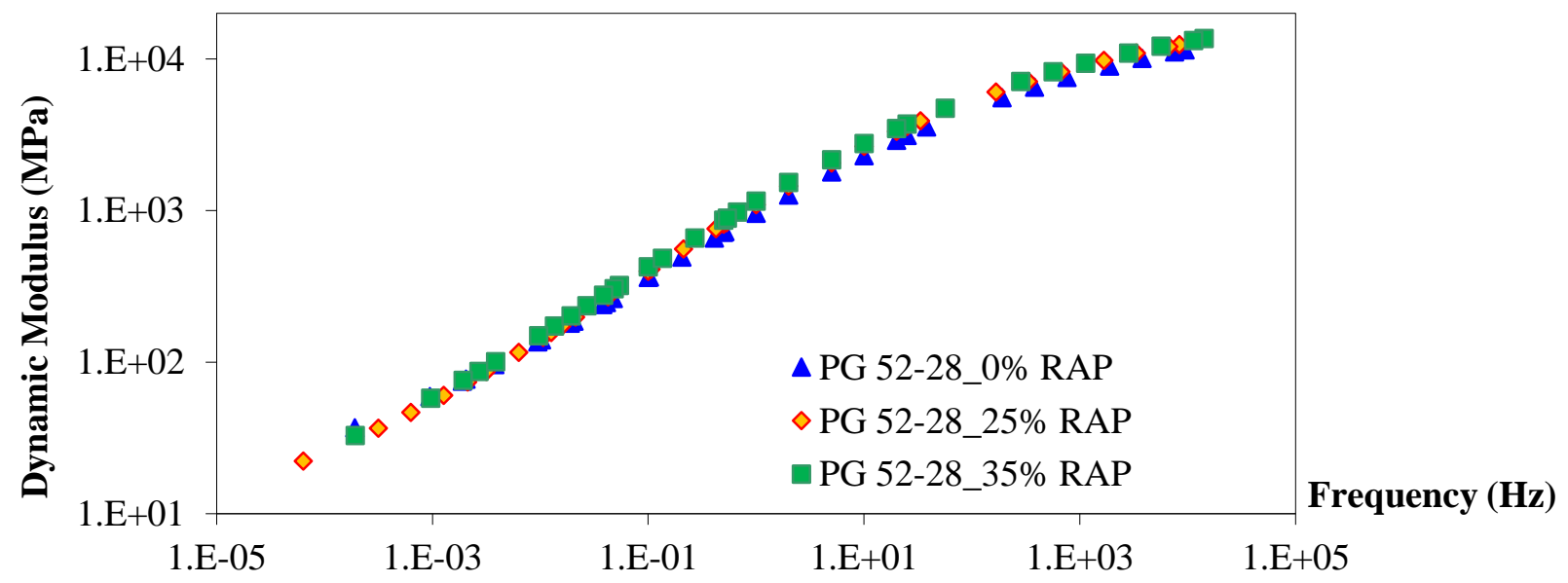

(a) Master Curve of PG 52-28 Mixes

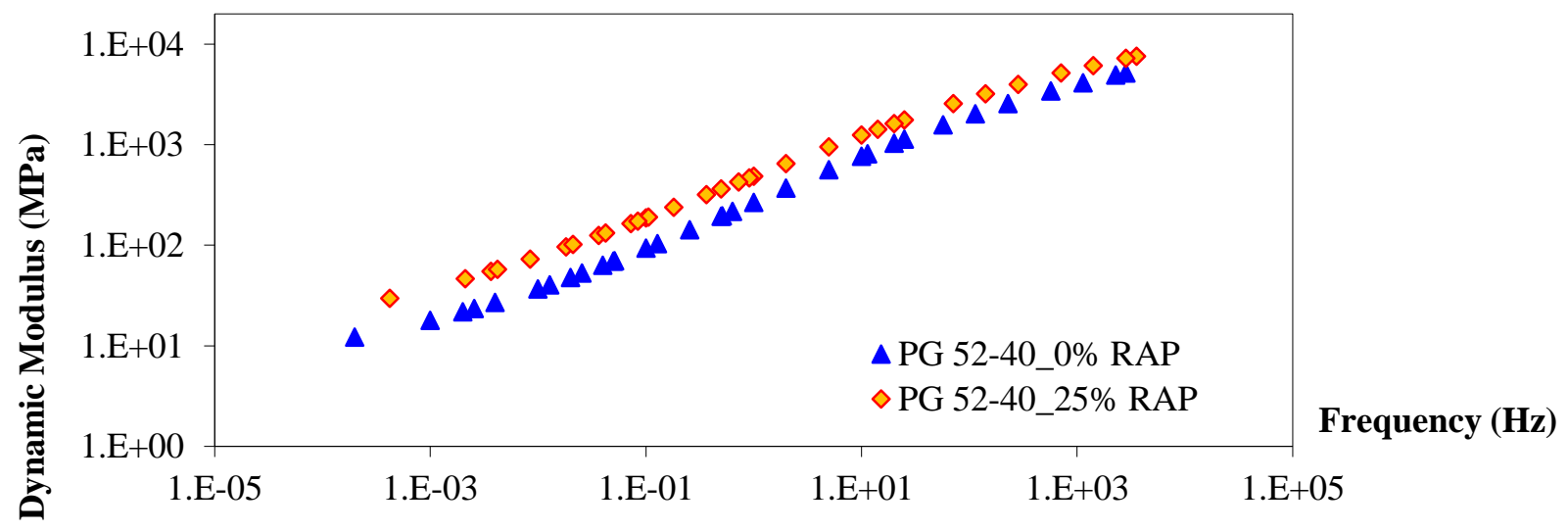

(b) Master Curve of PG 52-40 Mixes

Figure 6. Master Curves 
Figure 7 presents the flow number results. The addition of RAP was found to increase the flow number of both PG 52-28 and PG 52-40 mixes, with higher RAP content leading to higher flow number, namely higher rut-resistance. This finding was consistent with that from dynamic modulus results. The higher RAP content, the higher flow number was observed.

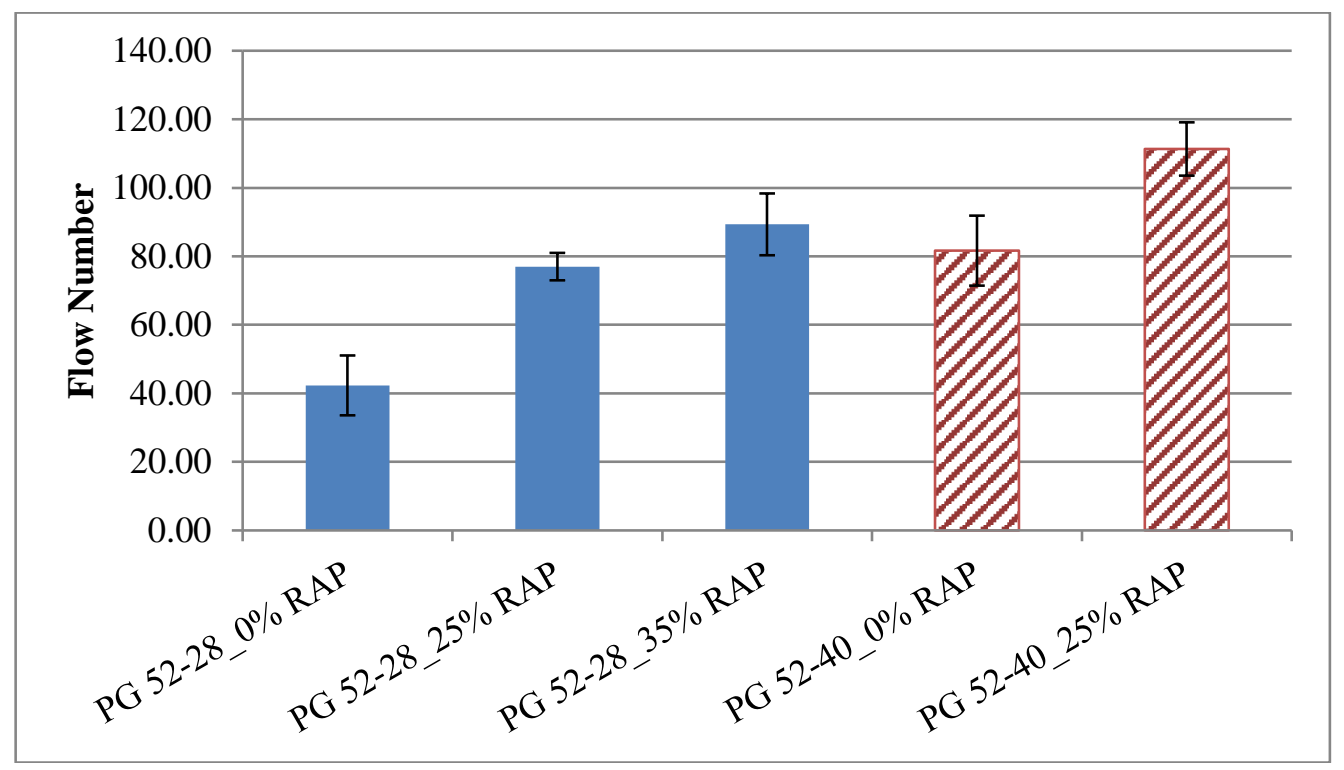

Figure 7. Flow Number Results

Figure 8 presents the IDT creep stiffness results with PG 52-28 mixes tested at $0{ }^{\circ} \mathrm{C},-10{ }^{\circ} \mathrm{C},-20{ }^{\circ} \mathrm{C}$, and PG 52-40 mixes tested at $-10{ }^{\circ} \mathrm{C},-20{ }^{\circ} \mathrm{C},-30{ }^{\circ} \mathrm{C}$. The results calculated at $100 \mathrm{~s}, 500 \mathrm{~s}$, and $1000 \mathrm{~s}$ are reported in sub-figures, respectively. The data at different loading time generally followed the same trend. Lower temperature led to higher creep stiffness of HMA, indicating potentially lower resistance to low temperature cracking. Adding RAP increased the creep stiffness of the mixture regardless of testing temperature. The higher the RAP content, the higher the creep stiffness of HMA. The results were consistent on both PG 52-28 mixes and PG 52-40 mixes produced with materials from the ADOT\&PF Northern Region.

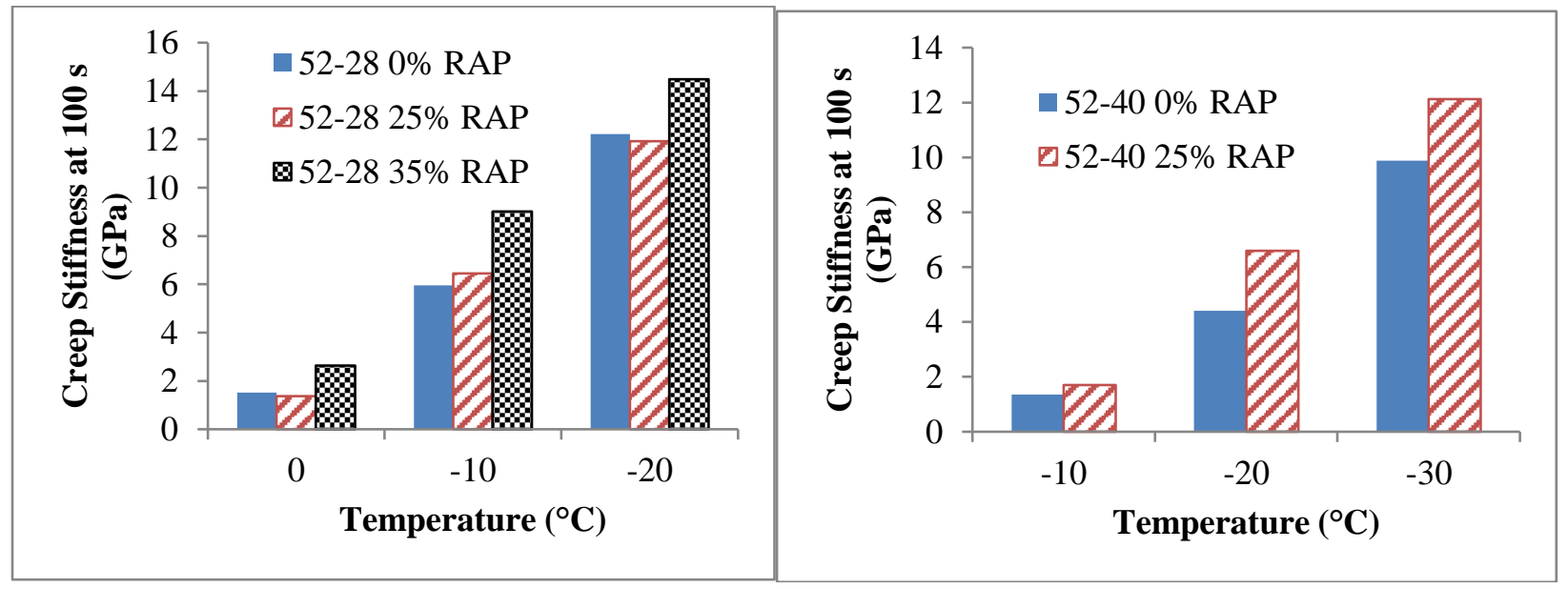

(a) Creep Stiffness Results at $100 \mathrm{~s}$ 


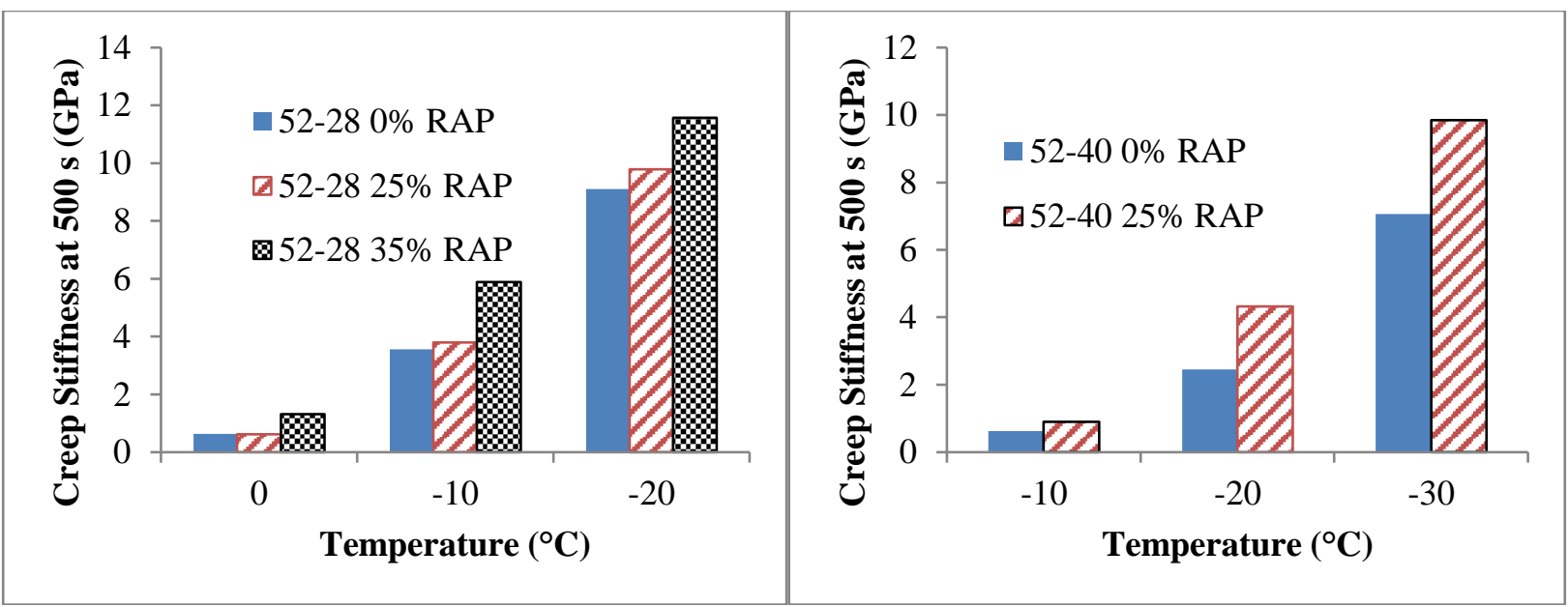

(b) Creep Stiffness Results at $500 \mathrm{~s}$

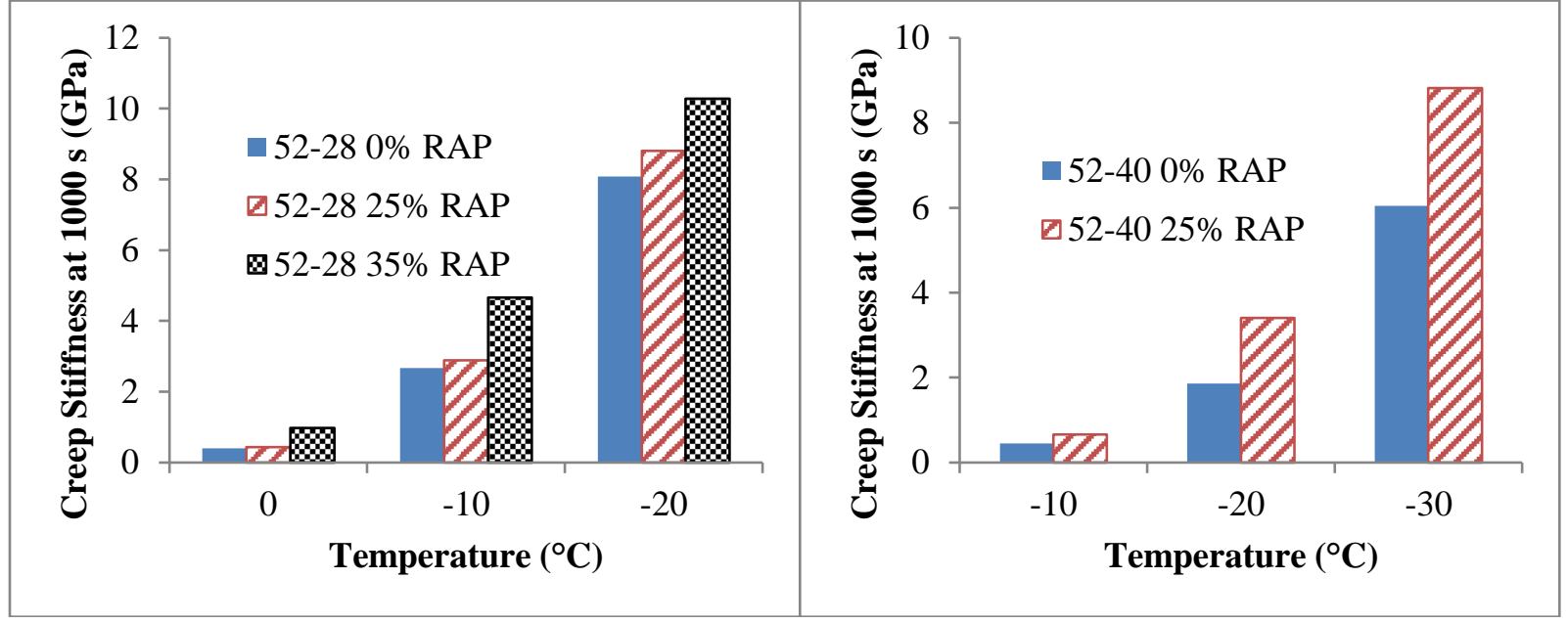

(c) Creep Stiffness Results at $1000 \mathrm{~s}$

Figure 8. Creep Stiffness Results

\section{SUMMARY AND CONCLUSION}

This study conducted dynamic modulus, flow number and IDT creep tests to characterize HMA containing RAP produced with Alaska materials. Five mixes were evaluated covering various RAP contents and two binders typically used in the ADOT\&PF Northern Region. It was found that adding RAP led to higher dynamic modulus and flow number, indicating higher potential rutting resistance of the mixture. Adding RAP increased the IDT creep stiffness of the mixture regardless of testing temperature, which could potentially result in a lower resistance to low temperature cracking. The results were consistent on both PG 52-28 mixes and PG 52-40 mixes produced with materials from the ADOT\&PF Northern Region. These findings showed that Alaskan HMA containing RAP generally follow the trend of RAP mix observed in literature conducted in other states, even though they were drawn based on preliminary testing on limited mixtures. It is recommended that more mixes in Alaska be evaluated in future studies covering other performance related tests, especially those designed for evaluation of low temperature cracking. 


\section{REFERENCES}

AASHTO T 342. (2013). "Determining Dynamic Modulus of Hot Mix Asphalt (HMA)." American Association of State Highway and Transportation Officials, 18 pages.

AASHTO TP 79. (2013). "Determining the Dynamic Modulus and Flow Number for Asphalt Mixtures Using the Asphalt Mixture Performance Tester (AMPT)." American Association of State Highway and Transportation Officials, 19 pages.

AASHTO T 322. (2013). "Determining the Creep Compliance and Strength of Hot Mix Asphalt (HMA) Using the Indirect Tensile Test Device." American Association of State Highway and Transportation Officials, 11 pages.

Al-Qadi, I. L., Elseifi, M. A., and Carpenter, S. H. (2007). "Reclaimed Asphalt Pavement - A Literature Review." Research Report FHWA-ICT-07-001, Federal Highway Administration, Washington, D.C

Behnia, B., Ahmed, S., Dave, E., and Buttlar, W. (2010). "Fracture Characterization of Asphalt Mixtures with Reclaimed Asphalt Pavement." International Journal of Pavement Research and Technology, 3(2), 72-78.

Bonaquist, R. (2007). “Can I Run More RAP?” Hot Mix Asphalt Technology, 12(5), 11-12

Bowers, B. F., Huang, B., Shu, X., and Miller, B. C. (2014). "Investigation of Reclaimed Asphalt Pavement Blending Efficiency through GPC and FTIR." Construction and Building Materials, 50, 517-523.

Connor, B., and Li, P. (2009). "Evaluation of the Addition of 15\% Recycled Asphalt Pavement." Research Report, Alaska Transportation Research Center, AK.

Hajj, E. Y., Sebaaly, P. E. and Kandiah, P. (2008). "Use of Reclaimed Asphalt Pavements (RAP) in Airfields HMA Pavements.” Final Report AAPTP Project, (05-06).

Huang, B., Xiang Shu, X., and Vukosavljevic, D. (2011). "Laboratory Investigation of Cracking Resistance of Hot-Mix Asphalt Field Mixtures Containing Screened Reclaimed Asphalt Pavement." Journal of Materials in Civil Engineering, 23, 1535-1543

Huang, B., Zhang, Z., and Kinger, W. (2004). "Fatigue Crack Characteristics of HMA Mixtures Containing RAP." Proceedings, 5th International RILEM Conference on Cracking in Pavements, Limoges, France.

Kandhal, P. S., and Mallick, R. B. (1997). "Pavement Recycling Guidelines for State and Local Governments - Participant's Reference Book." Report No. FHWA-SA-98-042, National Center for Asphalt Technology, Auburn, AL.

McDaniel, R. S., and Anderson, R. M. (2001). "Recommended Use of Reclaimed Asphalt Pavement in the Superpave Mix Design Method: Technician's Manual." NCHRP Report 452, Transportation Research Board, Washington, D.C.

Sabounjian, S. and Teclemariam, S. (2010). "Performance Grade of asphalt containing RAP." Research Report, AKDOT\&PF, AK.

West, R., Willis, J. R., and Marasteanu, M. (2013). "Improved Mix Design, Evaluation, and Materials Management Practices for Hot Mix Asphalt with High Reclaimed Asphalt Pavement Content." NCHRP Report 752, Transportation Research Board, Washington, D.C 
Willis, J. R., Turner, P., Julian, G., Taylor, A. J., Tran, N., and Padula, F. (2012). "Effects of Changing Virgin Binder Grade and Content on RAP Mixture Properties." NCAT Report 12-03, National Center for Asphalt Technology, Auburn, AL.

Zaumanis, M. and Mallick, R. B. (2014). "Review of Very High-Content Reclaimed Asphalt Use in Plant-Produced Pavements: State of the Art." International Journal of Pavement Engineering, 1-17.

Zhao, S., Huang, B., Shu, X., and Woods, M. (2013). "Comparative Evaluation of Warm Mix Asphalt Containing High Percentages of Reclaimed Asphalt Pavement." Construction and Building Materials, $44,92-100$.

Zhao, S., Huang, B., and Shu, X. (2015). "Investigation on Binder Homogeneity of RAP/RAS Mixtures through Staged Extraction.” Construction and Building Materials, 82, 184-191. 